\title{
Diaphragmatic dysfunction and dyspnoea in amyotrophic lateral sclerosis
}

\author{
T. Similowski*,\#, V. Attali*, G. Bensimon**, F. Salachas***, S. Mehiri*,\#, I. Arnulf*,\#, \\ L. Lacomblez***, M. Zelter ${ }^{+, \#}$, V. Meininger***, J-Ph. Derenne, ${ }^{*, \#}$
}

Diaphragmatic dysfunction and dyspnoea in amyotrophic lateral sclerosis. T. Similowski, V. Attali, G. Bensimon, F. Salachas, S. Mehiri, I. Arnulf, L. Lacomblez, M. Zelter, V. Meininger, J-Ph Derenne. (C)ERS Journals Ltd 2000.

ABSTRACT: Amyotrophic lateral sclerosis (ALS) is a progressive disorder of unknown origin. Respiratory involvement is the principal cause of death, and dyspnoea is a major source of discomfort.

In this study, diaphragm function is described and its relationship with dyspnoea examined in 48 ALS patients (32 male, age 26-80 yrs). The detailed neurological and respiratory evaluation (clinical examination, pulmonary function tests, static pressures, mouth twitch pressures $\left(P_{m}, t\right)$, electromyographic responses to phrenic nerve stimulation and cortical magnetic stimulation were analysed after stratification according to dyspnoea.

Dyspnoeic (group I) and nondyspnoeic (group II) patients were similar, bulbar signs being more frequent in group I. Vital capacity was lower in group I (mean \pm SD $67.9 \pm 22.7$ versus $87.9 \pm 15.6 \%$ of the predicted value, $p=0.0028$ ), as were maximal static inspiratory pressure $(41 \pm 24$ versus $60 \pm 27 \%$ pred, $p=0.0242)$ maximal static inspiratory pressure $(18 \pm 11$ versus $32 \pm 14 \%$ pred, $\mathrm{p}=0.0042)$, and $P \mathrm{~m}, \mathrm{t}(3.71 \pm 2.5$ versus $\left.7.26 \pm 3.45 \mathrm{cmH}_{2} \mathrm{O}, \mathrm{p}=0.0011\right)$. Abdominal (Abd) paradox and respiratory pulse were frequent in group I (15 of 25 and 14 of 25$)$ but absent or rare in group II (0 of 23 and four of 23$)(\mathbf{p}<0.05)$. The electromyographic responses to phrenic and cortical stimulation were generally abnormal in group I but subnormal in group II. Multivariate analysis selected only signs of diaphragm dysfunction (namely, Abd paradox and abnormal electromyographic responses) as significant predictors of dyspnoea.

It is concluded that dyspnoea in amyotrophic lateral scelrosis patients should prompt diaphragm function tests.

Eur Respir J 2000; 15: 332-337.
*Laboratoire de Physiopathologie Respiratoire du Service de Pneumologie, **Service de Pharmacologie Clinique, ***Service de Neurologie, and ${ }^{+}$Service Central d'Explorations Fonctionnelles Respiratoires Groupe Hospitalier Pitié-Salpetrière Paris, France. ${ }^{\#}$ Unité Propre de Recherche de L'Enseignement supérieur EA 2397, Université Paris VI, France.

Correspondence: T. Similowski, Laboratoire de Physiopathologie Respiratoire, Service de Pneumologie et de Réanimation, Groupe Hospitalier Pitié-Salpetrière, 47-83, Bd de l'Hôpital, 75651 Paris Cedex 13, France. Fax: 33142176708

Keywords: Amyotrophic lateral sclerosis, cerebral cortex, diaphragm, magnetic stimulation, phrenic nerve, respiratory muscles

Received: December 91998

Accepted after revision September 241999

This study was supported, in part, by a grant from the French Comite National contre les Maladies Respiratoires et la Tuberculose (CNMRT).
Amyotrophic lateral sclerosis (ALS) is a progressive fatal neurodegenerative disorder of unknown origin. Degeneration of spinal motor neurons is the main feature of the disease, but motor nuclei of the lower brainstem and upper neurons of the motor cortex are often involved [1]. There is no effective treatment apart from the recent demonstration of activity of an antiglutamate compound, which inhibits the metabolism of glutamate, riluzole [2, $3]$. The course of the disease is inexorable and linearly progressive, with a median survival time of 36-48 months [4] and many deaths related to respiratory events. Infrequent at the time of diagnosis despite early functional abnormalities [5], dyspnoea is considered the result of severe respiratory muscle weakness. It is a major source of discomfort and of psychological disturbance.

Any or all of the three muscle groups that are essential for normal ventilation, inspiratory, expiratory and upper airway muscles [6] can be impaired in ALS. Several lines of evidence point to the diaphragm as an important determinant of ALS-related respiratory insufficiency. Phrenic motoneurons are located in regions very likely to be involved by the disease [7], and there are major morphometric abnormalities in the phrenic nerve [8]. Never- theless, although it is widely accepted that diaphragm abnormalities are frequent in ALS, diaphragm function has neither been described in detail nor put in the perspective of dyspnoea.

The present study was thus undertaken to provide such information, using nonvolitional and noninvasive tests of diaphragm function in response to cervical magnetic stimulation-(CMS)- [9] and to cortical magnetic stimulation -(CxMS)- [10] in 48 patients grouped according to the presence or absence of dyspnoea.

\section{Patients and methods}

\section{Patients}

48 patients with definite ALS (table 1) [11] were studied for 12 months. Initially, 25 patients with dyspnoea ("breathing-related difficulties in relation to activities of daily living") were enrolled (group I) and then a control group (similar ALS duration and manual muscle testing (MMT) results) of 23 nondyspnoeic patients was constituted (group II). The exclusion criteria were associated respiratory 
Table 1. - Patient characteristics and neurological evaluation

\begin{tabular}{|c|c|c|c|}
\hline & Group I & Group II & p-value* \\
\hline Subjects $n$ & 25 & 23 & \\
\hline Age yrs & $\begin{array}{c}60.88 \pm 9.49 \\
(43-74)\end{array}$ & $\begin{array}{c}57.00 \pm 12.52 \\
(26-80)\end{array}$ & 0.1997 \\
\hline Sex & $15 \mathrm{M} / 10 \mathrm{~F}$ & $17 \mathrm{M} / 6 \mathrm{~F}$ & 0.3685 \\
\hline Weight kg & $\begin{array}{c}63.00 \pm 11.14 \\
(44-98)\end{array}$ & $\begin{array}{c}68.79 \pm 12.22 \\
(48-95)\end{array}$ & 0.0270 \\
\hline Height $\mathrm{cm}$ & $\begin{array}{c}167.08 \pm 8.53 \\
(147-187)\end{array}$ & $\begin{array}{c}168.48 \pm 7.409 \\
(150-180)\end{array}$ & 0.4693 \\
\hline $\begin{array}{l}\text { Body mass } \\
\text { index } \mathrm{kg} \cdot \mathrm{m}^{-2}\end{array}$ & $\begin{array}{l}22.58 \pm 3.77 \\
(16.1-33.9)\end{array}$ & $\begin{array}{l}24.47 \pm 3.16 \\
(18.2-29.7)\end{array}$ & 0.0410 \\
\hline $\begin{array}{l}\text { Disease duration } \\
\text { months }\end{array}$ & $\begin{array}{c}20.52 \pm 19.94 \\
(3-84)\end{array}$ & $\begin{array}{c}22.69 \pm 18.12 \\
(8-94)\end{array}$ & 0.1854 \\
\hline $\begin{array}{l}\text { Bulbar signs at } \\
\text { time of study } n^{\S}\end{array}$ & 20 & 7 & 0.0015 \\
\hline $\begin{array}{l}\text { Limb functional } \\
\text { score }(63)^{+}\end{array}$ & $\begin{array}{c}43.12 \pm 12.86 \\
\quad(5-60)\end{array}$ & $\begin{array}{c}47.96 \pm 12.07 \\
(23-63)\end{array}$ & 0.0921 \\
\hline $\begin{array}{l}\text { Bulbar functional } \\
\text { score }(39)^{+}\end{array}$ & $\begin{array}{l}28.92 \pm 7.505 \\
\quad(5-37)\end{array}$ & $\begin{array}{c}35.22 \pm 8.72 \\
(14-38)\end{array}$ & 0.0004 \\
\hline $\begin{array}{l}\text { Manual muscle } \\
\text { score }(150)^{+}\end{array}$ & $\begin{array}{c}109.16 \pm 25.85 \\
(45-140)\end{array}$ & $\begin{array}{c}121.26 \pm 15.48 \\
(87-147)^{\#}\end{array}$ & 0.1512 \\
\hline
\end{tabular}

Data are presented as mean \pm SD (range). *: Mann-Whitney test for continuous variables and Chi-squared test for dichotomous variables; ${ }^{\S}$ : number of patients; ${ }^{+}$: maximal value shown in parenthesis; ${ }^{\#}$ : n=22. M: male; F: female.

diseases, a cumulative tobacco consumption of $>15$ packyrs, recent (within the last 6 weeks) acute respiratory symptoms, end-stage disease and contraindications for magnetic stimulation [10]. None of the patients were on a medication known to interfere with the tests. The study involved only routine noninvasive techniques. All the patients were informed of its purpose and methods and gave consent to participate. For a given patient, all tests were performed within 1 week.

\section{Methods}

Neurological assessment. The duration of disease and the presence of bulbar signs at the time of respiratory assessment were recorded. Clinical status was evaluated using Norris limb and bulbar scales and MMT [3].

Respiratory assessment Dyspnoea. Patients in group I were asked to evaluate how intense their dyspnoea was on a $10-\mathrm{cm}$ visual analogue scale bounded by zero ("no breathing difficulty at all") on its leftmost side and 10 ("extreme difficulty") on its rightmost side and on which nine evenly spaced segments were marked with simple ticks. The procedure was repeated on two separate occasions. When the two values differed, the lowest one was retained. By definition, the dyspnoea score was zero in group II.

Clinical respiratory examination. A detailed respiratory examination was conducted, with emphasis on abdominal (Abd) paradox during resting respiration in the sitting position and respiratory pulse (inspiratory contraction of inspiratory neck muscles (INMs) during quiet breathing). This was evaluated by a clinician blind to the aim and design of the study, pulmonary function test results, and dyspnoea status.
Ribcage and abdominal displacement. Upper ribcage (RC) and Abd displacement were assessed using two mechanical strain gauges (Nihon Kohden, Tokyo, Japan), cross-calibrated but not calibrated in absolute terms.

Pulmonary function tests. Standard pulmonary function tests (spirometry and flow/volume curves; Pulmonet III; Gould, Cleveland, OH, USA) [12] were performed in 40 patients, 21 in group I and, 19 in group II. Functional residual capacity was measured in 24 patients (13 in group I and, 11 in group II) using the helium-dilution technique, and total lung capacity and residual volume (RV) were computed from a maximal inspiration and expiration.

Mouth pressure. Static mouth pressure $(P \mathrm{~m}, \mathrm{st})$ was measured using an occluded cylindrical semirigid rubber mouthpiece with a small leak $\left( \pm 150 \mathrm{cmH}_{2} \mathrm{O}\right.$, Validyne DP45 pressure transducer; Validyne, Northridge, CA, USA) [13]. $P$ m,st in response to CMS (mouth twitch pressure $(P \mathrm{~m}, \mathrm{t})$ ) was measured with the transducer attached to a side tap of the mouthpiece.

Electromyograms. Surface recordings of the right and left diaphragmatic electromyograms (EMGdi) were obtained using disposable silver electrodes taped to the skin in the 78th intercostal spaces and connected to a Nihon Kohden electromyograph (Nihon Kohden) (analogue-to-digital conversion $50 \mathrm{kHz}$, band pass $10 \mathrm{~Hz}$ to $2 \mathrm{kHz}$ ).

Phrenic nerve stimulation. Phrenic nerve stimulation was performed at end expiration in sitting patients, using CMS as previously described (Magstim 200; the Magstim Company, Sheffield, UK; 90-mm circular coil, maximum output $2.5 \mathrm{~T}$ ) [9]. The response to CMS was observed in terms of EMG, $P$ m,t and RC/Abd displacements. In order to eliminate twitches with a high likelihood of impeded pressure transmission to the mouth, $P$ m,t values were the mean of three to five twitches fulfilling three criteria: 1) similar amplitude $( \pm 5 \%) ; 2)$ peak of pressure preceding peak of Abd displacement; and 3) adequate rate of rise of pressure and regular shape.

Cortical magnetic stimulation. Cortical magnetic stimulation (CxMS) was delivered using the same apparatus as for CMS, at the end of a normal expiration (as described in [10]).

Electromyogram data handling. The latency of an electromyogram (EMG) response to stimulation (M-wave for CMS, motor-evoked potential, (MEP) for CxMS) was defined as the time between stimulation and the first departure from baseline. Abnormal responses to CxMS were delayed MEPs or the absence of MEP. For the purpose of statistical analysis, a continuous numerical variable was thus created from cortex-to-diaphragm conduction times (CDCT). An absence of response was assigned a value of zero, and responses, when present, were expressed as $1 / \mathrm{CDCT}$. The resulting global index was inversely related to the "quality" of the response to CxMS, accounting for abnormalities at any level from the cortex to the diaphragm.

\section{Statistical analysis}

Statistical analysis was performed using Statview (Abacus, Berkeley, CA, USA) and SPSS 6.1 (SPSS, Chicago, IL, USA). Data are presented as mean \pm SD. A p-value $<0.05$ 
is considered significant. Right-to-left side comparisons of EMG data were performed using a two-tailed Student's paired t-test. As no statistical difference was detected, right and left values were pooled for subsequent steps. Differences between groups were assessed using the MannWhitney test (continuous variables) or a Chi-squared test (dichotomous variables). Risk factors for dyspnoea were assessed in the whole study population using stepwise forward logistic regression and the likelihood ratio test. In group I, linear regression of the dyspnoea score with continuous variables was performed. Continuous variables significantly related to dyspnoea or close to being so were introduced into a multiple regression model. Dichotomous variables significantly different between group I and group II were recoded ("0" for "no", "1" for "yes") and introduced into a stepwise multiple regression model. Missing data were replaced by the mean value of the corresponding variable.

\section{Results}

Comparison of the 48 patients stratified according to dyspnoea

Descriptive data. Bulbar signs were more marked in group I, in which patients were of lower weight and body mass index (BMI) (higher proportion of females) (table 1).

Respiratory assessment. In group I, the dyspnoea score was $4.64 \pm 2.25$ ( $\geq 4$ in 12 cases), respiratory pulse and Abd paradox were significantly more frequent and vital capacity (VC) lower than in group II (table 2). Maximal expiratory $(P I, \max )$ and inspiratory pressure $(P \mathrm{E}, \max )$ were reduced in both groups, dramatically so in group I. Flow/ volume curves suggested upper airway instability in eight group I patients (seven bulbar), versus three in group II (two bulbar) (NS).

Cervical magnetic stimulation. In group II, CMS evoked bilateral M-wave responses (phrenic nerve conduction time (PNCT) $7.90 \pm 1.67 \mathrm{~ms}$ ) in all patients but one (figs. 1 and 2 ). In this single case, CMS-related Abd expansion excluded diaphragm paralysis and meant that a technical problem was most likely. In group I, two patterns could be identified. Sixteen patients showed Abd expansion and a bilateral M-wave response (PNCT $8.28 \pm 1.75 \mathrm{~ms}$, not different from group II). In the remaining nine patients, CMS induced a decrease in Abd circumference. There was no discernible EMG response on either side in four of these, and a unilateral delayed response $(>10 \mathrm{~ms})$ in five. This indicates diaphragm paralysis or near-paralysis [14], probably due to denervation atrophy [15]. PNCTs in both groups were greater than normal $(<6 \mathrm{~ms}[16])$.

$P$ m,t was measured in 19 patients in group I $(3.71 \pm 2.50$ $\left.\mathrm{cmH}_{2} \mathrm{O}\right)$ and 17 in group II $\left(7.26 \pm 3.45 \mathrm{cmH}_{2} \mathrm{O} \mathrm{p}=0.0011\right)$. Signs of "glottis closure" were noted in $<5 \%$ of twitches (probably due to $P$ m,t being too low to destabilize the upper airways [17] and perhaps to some degree of UA spasticity).

Cortical magnetic stimulation. In group II, a bilateral response was observed in all but one case (see above) (17.58 $\pm 1.71 \mathrm{~ms}$, normal value $17.4 \pm 1.1 \mathrm{~ms}$ [10]) (figs. 1 and 2). In group I, 13 patients showed a bilateral response
Table 2. - Respiratory evaluation

\begin{tabular}{|c|c|c|c|}
\hline & Group I & Group II & p-value* \\
\hline Subjects $n$ & 25 & 23 & \\
\hline Dyspnoea & $4.64 \pm 2.25$ & $0^{+}$ & \\
\hline \multicolumn{4}{|l|}{$\begin{array}{l}\text { Clinical respiratory } \\
\text { assessment }\end{array}$} \\
\hline Respiratory pulse & 14 & 4 & 0.0138 \\
\hline $\begin{array}{l}\text { Paradoxical res- } \\
\text { piration }\end{array}$ & 15 & 0 & 0.0006 \\
\hline \multicolumn{4}{|l|}{$\begin{array}{l}\text { Pulmonary } \\
\text { function tests }\end{array}$} \\
\hline VC \% pred & $\begin{array}{l}67.86 \pm 22.73 \\
(27-115 ; 21)\end{array}$ & $\begin{array}{l}87.87 \pm 15.57 \\
(38-109 ; 19)\end{array}$ & 0.0028 \\
\hline FRC \% pred & $\begin{array}{l}98.23 \pm 27.60 \\
(54-151 ; 13)\end{array}$ & $\begin{array}{l}93.36 \pm 16.96 \\
(68-116 ; 11)\end{array}$ & 0.7499 \\
\hline TLC $\%$ pred & $\begin{array}{l}82.00 \pm 17.89 \\
(50-116) ; 13\end{array}$ & $\begin{array}{c}91.09 \pm 9.85 \\
(80-110 ; 11)\end{array}$ & 0.2458 \\
\hline RV \% pred & $\begin{array}{l}109.85 \pm 30.41 \\
(63-163 ; 13)\end{array}$ & $\begin{array}{l}94.91 \pm 14.26 \\
(73-115 ; 11)\end{array}$ & 0.1396 \\
\hline FEV1 \% pred & $\begin{array}{l}66.90 \pm 23.87 \\
(30-122 ; 21)\end{array}$ & $\begin{array}{l}90.41 \pm 16.93 \\
(49-119 ; 19)\end{array}$ & 0.0009 \\
\hline FEV1/VC \% pred & $\begin{array}{c}99.30 \pm 12.79 \\
(78-123 ; 21)\end{array}$ & $\begin{array}{l}104.86 \pm 10.91 \\
(83-127 ; 18)\end{array}$ & 0.1628 \\
\hline \multicolumn{4}{|l|}{$\begin{array}{l}\text { Static pressures } \\
\text { at FRC }\end{array}$} \\
\hline$P \mathrm{I}, \max \%$ pred & $\begin{array}{c}41 \pm 24 \\
(5-101 ; 16)\end{array}$ & $\begin{array}{c}60 \pm 27 \\
(15-109 ; 15)\end{array}$ & 0.0242 \\
\hline$P$ E,max $\%$ pred & $\begin{array}{c}18 \pm 11 \\
(7-51 ; 16)\end{array}$ & $\begin{array}{c}32 \pm 14 \\
(12-54 ; 16)\end{array}$ & 0.0042 \\
\hline
\end{tabular}

Data are presented as mean \pm SD (range; $n)$. *: Mann-Whitney test for continuous variables and Chi-squared test for dichotomous viriables; ${ }^{+}$: by definition, see text. Data were compared to predicted values of pulmonary function test results [14] and static pressures at functional residual capacity (FRC) [15]. VC: vital capacity; TLC: total lung capacity; RV: residual volume; FEV1: forced expiratory volume in one second; $P \mathrm{I}$,max: maximal static inspiratory pressure; $P$ E,max: maximal static expiratory pressure.

$(18.76 \pm 1.74 \mathrm{~ms}, \mathrm{p}=0.0056)$. In three cases, the response was abolished unilaterally, in spite of a bilateral response to CMS. In nine cases, the response to CxMS was abolished bilaterally. These included the four patients with a bilaterally abolished response to CMS. Thus, in the remaining five cases, no response to CxMS was observed in spite of a persistent response to CMS. 1/CDCT was $3.45 \pm 2.67 \mathrm{~ms}^{-1}$ in group I, versus $5.49 \pm 1.33 \mathrm{~ms}^{-1}$ in group II, $p=0.0018$, (fig. 3 ). Because this index does not discriminate central from peripheral conduction abnormalities, the CDCT-PNCT difference was computed in patients with bilateral responses to both CxMS and CMS and found to be greater in group I $(11.66 \pm 3.21$ versus $9.64 \pm 2.28 \mathrm{~ms}, \mathrm{p}=0.0423$ ).

\section{Determinants of dyspnoea}

With dyspnoea as the dichotomous outcome, BMI, bulbar score, respiratory pulse, Abd paradox, PI,max, PE,max, $1 / C D C T$ and VC were used as independent variables in a stepwise logistic regression model (tables 1 and 2). Only two uncorrelated variables were significantly associated with dyspnoea, Abd paradox and 1/CDCT. The slopes of the linear regression equations with dyspnoea score as the 
a)

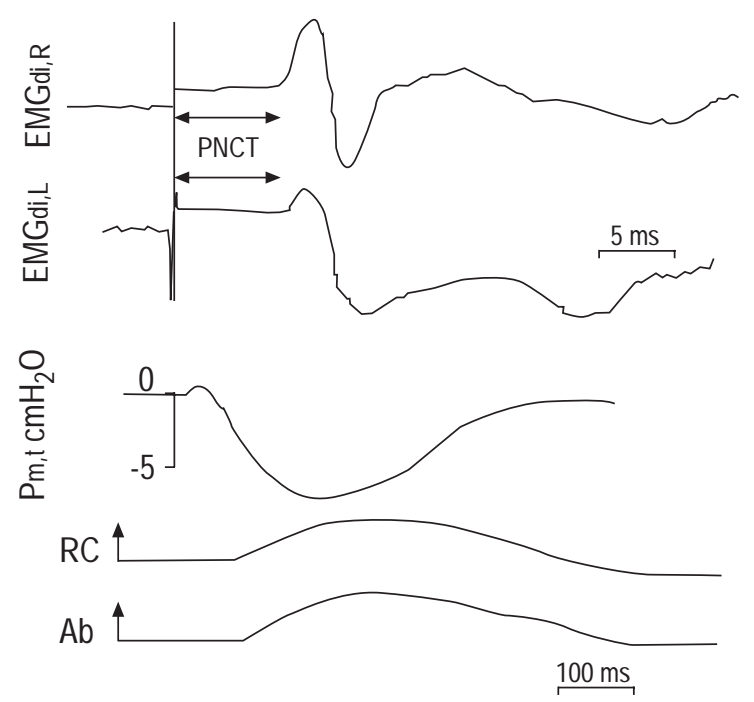

b)
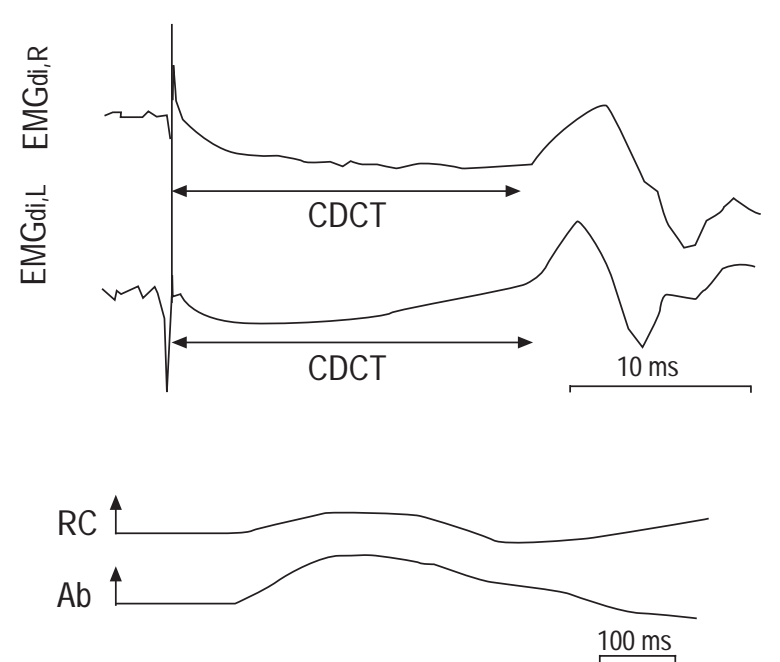

Fig. 1. - Response to: a) cervical magnetic stimulation (CMS); and b) cortical magnetic stimulation (CxMs) in a nondyspnoeic patient (group II), illustrating signals handling. Vertical arrows indicate abdominal (Abd) and ribcage (RC) circumference expansion (no absolute calibration). Note that, in this example, the CMS latency exceeds $7.5 \mathrm{~ms}$ and the amplitude of the mouth twitch pressure $(P \mathrm{~m}, \mathrm{t})$ is of $6.5 \mathrm{cmH}_{2} \mathrm{O}$, both abnormal values. No pressure response to CxMs was assessed, but RC and Abd displacements were recorded. Abd expansion ensures a diaphragm contribution to the observed motorevoked potential [10]. EMGdi,R,: right diagphragmatic electromyogram; EMGdi,L: left diaphragmatic electromyogram; PNCT: phrenic nerve conduction time; CDCT: cortex-to-diaphragm conduction time.

dependent variable were significant only for spirometric data, and relatively close to being so for bulbar score $(\mathrm{p}=0.0745)$, and $1 / \mathrm{CDCT}(\mathrm{p}=0.1177)$, and, to a lesser extent, $P \mathrm{~m}, \mathrm{t}(\mathrm{p}=0.1979)$. A linear multiple regression model using these variables predicted $52 \%$ of the variance of the dyspnoea score $(\mathrm{p}=0.0110)$. When dichotomous variables were added in a stepwise multiple regression analysis, only the bulbar score and respiratory pulse were significantly related to dyspnoea score.

\section{Comparison of patients stratified according to bulbar signs}

Groups I and II were not matched with respect to the proportion with bulbar signs that they included, hence this

a)

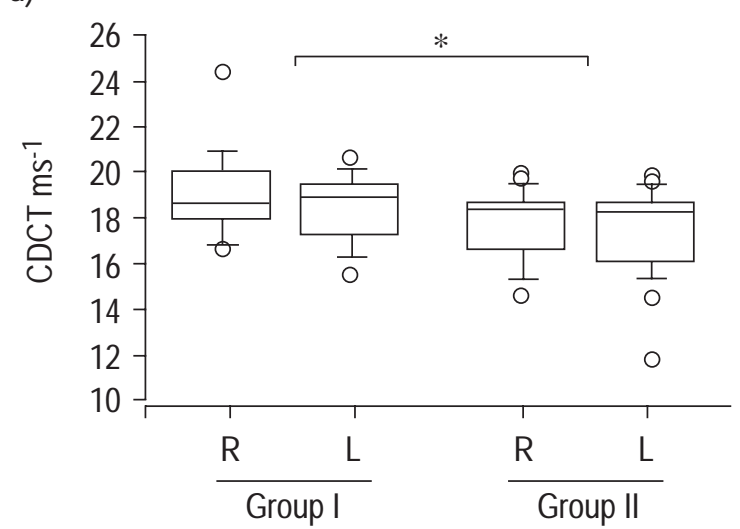

analysis. In the 27 patients with and the 21 without bulbar signs, disease duration, limb scale, and MMT results were not different, but bulbar patients had a lower BMI $(21.77 \pm$ 2.55 versus $25.7 \pm 3.5, \mathrm{p}=0.0003)$. Twenty of them had dyspnoea (score $3.51 \pm 2.94$ ), versus five of the 21 nonbulbar patients (score $1 \pm 2, \mathrm{p}=0.0018$ versus dyspnoea score in bulbar patients) $(\mathrm{p}=0.0015)$. VC was significantly lower (with higher RV) in bulbar patients, who had lower PI,max and $P$ E,max $(40.3 \pm 23.9$ and $18.9 \pm 10.5$ versus $62.4 \pm 25.6$ and $33.5 \pm 14 \%$ pred) and $P$ m,t $(4.14 \pm 2.92$ versus $7.13 \pm 3.45$ $\mathrm{cmH}_{2} \mathrm{O}$ ). In bulbar patients, dyspnoea was associated with a higher frequency of respiratory pulse and Abd paradox, and significantly lower VC, $P$ m,t, and $1 / C D C T$. Conversely to what was observed in the whole study population in which dyspnoeic patients had significantly lower $P \mathrm{I}$,max

b)

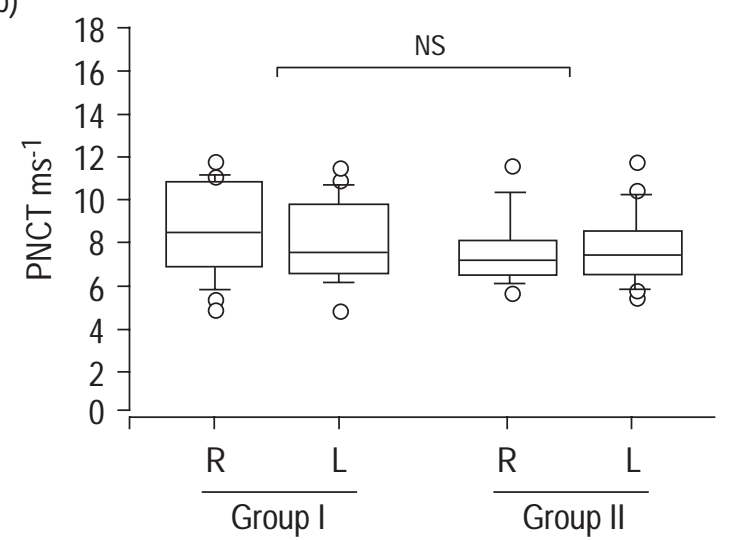

Fig. 2. - Box plots of right (R) and left (L): a) cortex-to-diaphragm conduction time (CDCT) in response to cortical magnetic stimulation; and b) phrenic nerve conduction time (PNCT) in response to cervical magnetic stimulation. In some patients, No R [12] and L [11] CDCT and R (six) and L (seven) PNCT could be measured; these were not taken into account in this comparison. Results on the right and left sides were comparable (paired t-test) and pooled for the comparison of group I and group II. *: $\mathrm{p}<0.05$. 


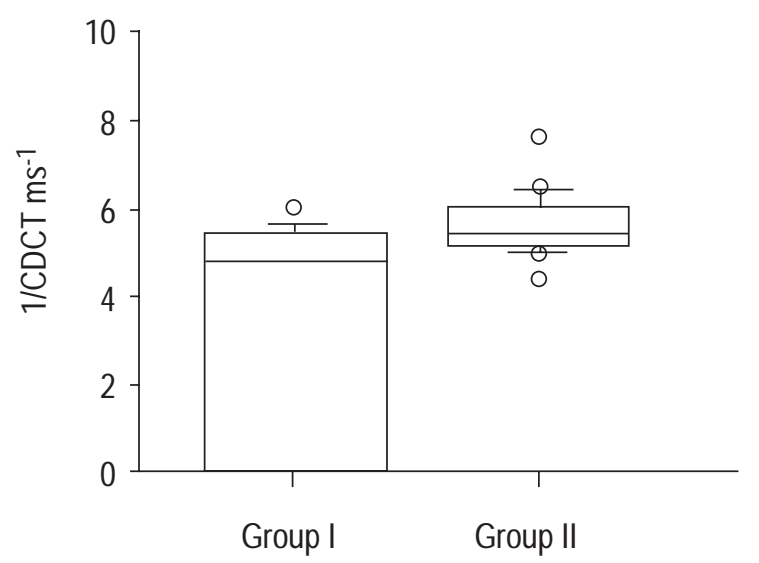

Fig. 3. - Box plot showing the inverse of cortex-to-diaphragm conduction time (1/CDCT) (absent responses are attributed the value zero, see text) in group I and group II. $\mathrm{p}<0.05$, group I versus group II.

and $P$ E,max than nondyspnoeic ones, $P \mathrm{I}$,max and $P$ E,max were not different between dyspnoeic bulbar patients and nondyspnoeic bulbar patients.

\section{Discussion}

This study shows, not surprisingly, impaired inspiratory and expiratory muscle function in ALS patients with a mean disease duration of 20-22 months. Diaphragm abnormalities were more pronounced in patients reporting dyspnoea.

\section{Global respiratory muscle alterations}

$P \mathrm{I}$,max and $P$ E,max were impaired in both groups (table 2 ), in line with previous reports $[5,13,18-20]$, but were significantly more reduced in dyspnoeic patients. As noted previously [19], respiratory pressures seemed more reduced than $\mathrm{VC}$, probably due to the absence of major abnormalities in respiratory mechanics allowing good volumes to be produced with minimal pressures. The RVs in the patients seem surprisingly close to normal in view of the decreased $P$ E,max, especially in group I (table 2). However, the distribution of RV was skewed to the right, with $61 \%$ of values above the population median (113$163 \%$ pred).

\section{Diaphragm dysfunction}

A limitation of this study is the absence of measurement of transdiaphragmatic pressure $(P \mathrm{di})$, use of which was deemed ethically questionable in a large population of patients, half of which had bulbar signs and deglutition impairment. This may explain, in part, the scarcity of balloon catheter measurements in the ALS literature. The combination of indexes gathered probably obviate the lack of $P$ di measurement. First, the physical signs accompanying diaphragm weakness support this contention. Secondly, Abd paradox in response to CMS (nine patients) indicates extreme diaphragm weakness. Thirdly, finding a $P \mathrm{~m}, \mathrm{t}$ of $<10 \mathrm{cmH}_{2} \mathrm{O}$ (threshold for the diagnosis of diaphragm weakness [21]) implies all the more diaphragm weakness in that $P \mathrm{~m}, \mathrm{t}$ can be the sum of a diaphragm component and an INM component [14]. The lower $P \mathrm{~m}, \mathrm{t}$ in group I thus indicates a greater degree of diaphragm dysfunction. Fourthly, the EMGdi responses to CMS and CxMS were most often abnormal, and more so in group I. Finally, in bulbar patients, global respiratory muscle indices were not different in the absence or presence of dyspnoea, whereas diaphragm indices were.

\section{Peripheral versus central diaphragm dysfunction}

In ALS, degeneration of the lower phrenic motor neurons leads to denervation atrophy. By analogy with other muscles [1], diaphragm dysfunction could also result from upper phrenic motor neurons degeneration. Abd paradox could thus be due either to intrinsic diaphragm weakness or to the impaired generation or transmission of central commands. Abd paradox during spontaneous breathing was probably "peripheral" in origin in the nine patients in group I in whom CMS induced a decrease in Abd circumference. It was probably "central" in origin in the other cases. Additional arguments in favour of a role of upper motor neuron abnormalities include the abolition of the EMG response to CxMS in spite of a persistent response to CMS in some cases, and significantly longer CDCTs in group I than in group II despite similar PNCTs (namely, greater CDCT/PNCT difference).

\section{Inspiratory neck muscles}

Fourteen patients in group I versus four in group II had a respiratory pulse, hence increased INM activity. In the subset of patients with CMS-induced Abd paradox, the $P \mathrm{~m}, \mathrm{t}$ response, not observed in patients with recent diaphragm paralysis [22], suggested improved mechanical efficiency of the INMs. Such a pattern has seemingly not been reported tor any other muscle group in ALS. The authors interpret this as the result of compensation for the progressive reduction in diaphragm strength, the work of breathing being gradually shifted from the diaphragm to the INMs. This could explain why VC was not dramatically lower in group I than in group II (see [14]).

\section{Determinants of dyspnoea}

Dyspnoeic patient had poorer pulmonary and respiratory muscle function than nondyspnoeic ones, a lower BMI and more bulbar involvement. None of these parameters were selected as risk factors for dyspnoea by the multivariate analysis, which retained only diaphragm indices. Nevertheless, in order to further isolate the role of diaphragmatic abnormalities in the pathogenesis of dyspnoea, the comparison was restricted to dyspnoeic and non dyspnoeic bulbar patients. There was no longer a difference in BMI and static pressures, and, except for VC, only diaphragm abnormalities were markedly more impaired in the presence of dyspnoea (Abd paradox, respiratory pulse, $P \mathrm{~m}, \mathrm{t}$ and 1/CDCT, see Results).

The presence of respiratory pulse among the limited number of parameters selected as predictors of the intensity of dyspnoea is interesting in view of the increased discomfort associated with the use of neck muscles rather than of the diaphragm to surmount an inspiratory load [23]. Some patients with dyspnoea showed preserved VC and PI,max (table 2), often in spite of signs of diaphragm dysfunction and always in conjunction with INM abnormalities. This illustrates how efficient can adaptive 
mechanisms can be and probably accounts for the variable performances of $\mathrm{VC}$ as an indicator of respiratory involvement in ALS $[5,24]$.

\section{Practical implications and perspectives}

Diaphragm abnormalities in ALS have several implications. Factors known to affect diaphragm function can be looked for and corrected. Since diaphragm fibre changes are likely to be heterogeneous, pharmacologically improving the function of the fibres not affected by degeneration could help maintain global diaphragm performance [18]. The unavoidable sleep-related aggravation $[25,26]$, principally during paradoxical sleep, cast a new light on nocturnal deaths, and could explain the benefits of nocturnal noninvasive ventilation in terms of quality of life and of survival [27].

In summary, the present study confirms that diaphragm dysfunction is common in amyotrophic lateral sclerosis, and shows that it can stem from upper motor neuron abnormalities and is linked to dyspnoea. The prognostic value of diaphragm dysfunction, the use of diaphragm tests for follow-up and the clinical relevance of "diaphragmoriented" strategies remain to be investigated. Indeed, as vital capacity and blood gas levels are poor indicators of respiratory insufficiency [5, 19, 24, 27], such strategies could avoid leaving patients with compromised diaphragm function but otherwise subnormal respiratory test results exposed to sleep-related respiratory disorders. Meanwhile, the authors submit that dyspnoea in amyotrophic lateral sclerosis should suffice to prompt diaphragm investigations and that diaphragm dysfunction should raise the issue of ventilatory support.

Acknowledgements. The authors are indebted to S. Kelly for help with the manuscript.

\section{References}

1. Urban PP, Vogt T, Hopf HC. Corticobulbar tract involvement in amyotrophic lateral sclerosis - a transcranial magnetic stimulation study. Brain 1998; 121: 1099-1108.

2. Bensimon G, Lacomblez L, Meininger V, the Amyotrophic Lateral Sclerosis/Riluzole study group. A controlled trial of riluzole in amyotrophic lateral sclerosis. $N$ Engl $J$ Med 1994; 330: 585-591.

3. Lacomblez L, Bensimon G, Leigh PN, et al. A confirmatory dose-ranging study of riluzole in ALS. Neurology 1996; 47: (Suppl. 4): S242-S250.

4. Jablecki CK, Berry C, Leach J. Survival prediction in amyotrophic lateral sclerosis. Muscle Nerve 1989; 12: 833-841.

5. Schiffman PL, Belsh JM. Pulmonary function at diagnosis of amyotrophic lateral sclerosis. Rate of deterioration. Chest 1993; 103: 508-513.

6. Garcia-Pachon E, Marti J, Mayos M, Casan P, Sanchis J. Clinical significance of upper airway dysfunction in motor neurone disease. Thorax 1994; 49: 896-900.

7. Tsukagoshi H, Yanagisawa N, Oguchi K, Nagashima K, Murakami T. Morphometric quantification of the cervical limb motor cells in controls and in amyotrophic lateral sclerosis. J Neurol Sci 1979; 41: 287-297.

8. Bradley WG, Good P, Rasool CG, Adelman LS. Morphometric and biochemical studies of peripheral nerves in amyotrophic lateral sclerosis. Ann Neurol 1983; 14: $267-$ 277.

9. Similowski T, Fleury B, Launois S, Cathala HP, Bouche P, Derenne JP. Cervical magnetic stimulation: a new painless method for bilateral phrenic nerve stimulation in conscious humans. J Appl Physiol 1989; 67: 1311-1318.

10. Similowski T, Straus C, Coïc L, Derenne JP. Facilitationindependent response of the diaphragm to cortical magnetic stimulation in conscious man. Am J Respir Crit Care Med 1996; 154: 1771-1777.

11. Brooks BR. El Escorial World Federation of Neurology criteria for the diagnosis of amyotrophic lateral sclerosis. J Neurol Sci 1994; 124 Suppl.: 96-107.

12. European Respiratory Society. Edition Française des Recommandations Européennes pour les Explorations Fonctionnelles Respiratoires. Rev Mal Respir 1994; 11: Suppl. 3.

13. Black L, Hyatt R. Maximal respiratory pressures: normal values and relationship to age and sex. Am Rev Respir Dis 1969; 99: 696-702.

14. Attali V, Mehiri S, Straus C, et al. Influence of neck muscles on mouth pressure response to cervical magnetic stimulation. Am J Respir Crit Care Med 1997; 156: 509-514.

15. Evangelista T, Carvalho M, Pinto A, Luis MdL. Phrenic nerve conduction in amyotrophic lateral sclerosis. J Neurol Sci 1995; 129 (Suppl. 2): 35-37.

16. Similowski T, Mehiri S, Attali V, Duguet A, Straus C, Derenne J-P. Comparison of magnetic and electrical phrenic nerve stimulation in assessment of phrenic nerve conduction time. J Appl Physiol 1997; 82: 1190-1199.

17. Series F, Demoule A, Marc I, Sanfacon C, Derenne J-P, Similowski T. Inspiratory flow dynamics during phrenic nerve stimulation in awake normals during nasal breathing. Am J Respir Crit Care Med 1999; 60: 614-620.

18. Schiffman PL, Belsh JM. Effect of inspiratory resistance and theophylline on respiratory muscle strength in patients with amyotrophic lateral sclerosis. Am Rev Respir Dis 1989; 139: 1418-1423.

19. Vitacca M, Clini E, Facchetti D, et al. Breathing pattern and respiratory mechanics in patients with amyotrophic lateral sclerosis. Eur Respir J 1997; 10: 1614-1621.

20. Polkey MI, Lyall RA, Green M, Nigel Leigh P, Moxham J. Expiratory muscle function in amyotrophic lateral sclerosis. Am J Respir Crit Care Med 1998; 158: 734-741.

21. Hamnegard CH, Wragg S, Kyroussis D, et al. Mouth pressure in response to magnetic stimulation of the phrenic nerves. Thorax 1995; 50: 620-624.

22. Mills GH, Kyroussis D, Hamnegard CH, et al. Cervical magnetic stimulation of the phrenic nerves in bilateral diaphragm paralysis. Am J Respir Crit Care Med 1997; 155: 1565-1569.

23. Ward ME, Eidelman D, Stubbing DG, Bellemare F, Macklem PT. Respiratory sensation and pattern of respiratory muscle activation during diaphragm fatigue. $J$ Appl Physiol 1988; 65: 2181-2189.

24. Fallat RJ, Jewitt B, Bass M, Kamm B, Norris FH Jr. Spirometry in amyotrophic lateral sclerosis. Arch Neurol 1979; 36: 74-80.

25. Bye PT, Ellis ER, Issa FG, Donnelly PM, Sullivan CE. Respiratory failure and sleep in neuromuscular disease. Thorax 1990; 45: 241-247.

26. Johnson MW, Remmers JE. Accessory muscle activity during sleep in chronic obstructive pulmonary disease. $J$ Appl Physiol 1984; 57: 1011-1017.

27. Aboussouan LS, Khan SU, Meeker DP, Stelmach K, Mitsumoto $H$. Effect of noninvasive positive-pressure ventilation on survival in amyotrophic lateral sclerosis. Ann Intern Med 1997; 127: 450-453. 